\title{
Prescribing pattern of higher generation antibiotics in the out-patient setting in Bhutan hospitals
}

\author{
Tashi Tobgaya , Tandin ${ }^{\mathrm{b}}$, Manusika Rai ${ }^{\mathrm{c}}$, Jens Aagaard-Hansen ${ }^{\mathrm{d}}$, Maria Vang Johansen, Ebba Holme Hansenf, \\ Birna Trap ${ }^{\mathrm{g}}$ \\ a,b Pharmacy Department, JDW/NR-Hospital, Thimphu, Bhutan; ${ }^{\circ}$ Essential drugs programme, Bhutan. \\ ${ }^{c, d}$ DBL-Institute for Health Research and Development, Copenhagen, Denmark. ${ }^{e}$ Department of Social \\ Pharmacy, The Danish University of Pharmaceutical Sciences, Copenhagen, Denmark. ${ }^{\mathrm{E}}$ Euro Health \\ Group, Soborg, Denmark
}

\begin{abstract}
Background: The emergence of antibiotic resistance is a complex problem contributed by the interplay of various parties such as prescribers, patients or health settings. In particular, prescribers play a vital role in the use of antibiotics both in rational prescribing of drugs and influencing patients on the appropriate use.

Objectives: Determine the appropriateness of the higher generation antibiotics (cephalosporin and flouroquonolone groups) in the out-patient setting of Bhutan hospitals.

Materials and method: A cross-sectional study was conducted in three referral hospitals of Bhutan where the prescriptions were collected from the pharmacy. All prescriptions containing higher generation antibiotics were selected based on the appropriateness using a modified Medication Appropriateness Index. Three hundred thirty three prescriptions containing higher generation antibiotics were analyzed.

Results: The use of antibiotics was common with $37.1 \%$ of the prescriptions containing antibiotics out of which $14 \%$ were higher generation antibiotics. When assessed on the appropriateness of the prescription, 55.9\% of the prescriptions containing higher generation antibiotics were prescribed inappropriately. In addition, only $47.1 \%$ of the prescriptions had appropriate indications for higher generation antibiotics.

Conclusion: There is a widespread inappropriate use of higher generation antibiotics in Bhutan.
\end{abstract}

Keywords: Antibiotics, Bhutan, medication appropriateness index, prescribing pattern, rational use

Infectious diseases are a major cause of deaths, and this is more prominent in the developing countries [1]. Antibiotics, combined with vaccinations, has produced a massive decline in mortality caused by bacterial infections [2]. The antibiotic resistance is a health problem leading to poor treatment outcome and increased cost [3].

Antibiotics resistance is contributed by the interplay of various parties such as prescribers, patients, health settings, medicines used, dispensers, private parties, and animal husbandry [4]. The inappropriate antibiotic use, including overuse, use in wrong indications, mode of use, under- or over-use, poor adherence, and poor quality of drugs, may also contribute to the antibiotic resistance [5-7].

Correspondence to: Tashi Tobgay, Pharmacy Department, JDW/NR-Hospital, Thimphu, Bhutan. E-mail: tobgayla2000@ gmail.com
Okeke et al. [8] described various problems in the use of antibiotics in developing countries leading to a rapid development of resistance to antibiotics. Although antimicrobial resistance is rampant, there are limited studies on determining the best model for improving the use of antibiotics [9-11].

The Bhutan Essential Drugs Program (EDP) was launched in 1986 with an objective to ensure the regular supply of safe, effective, and need-based drugs of acceptable quality at reasonable cost to the majority of the population and promote and monitor rational prescribing, good storage, and dispensing practices. According to the report by Ministry of Health, Bhutan, expenditure on antibiotics is about $17 \%$ of the total drug budget, which is about USD 1.4 million per year for a population of about 635,000. The higher generation antibiotic available on the Essential Drug List (EDL) is ciprofloxacin and norfloxacin among 
fluoroquonolones, and ceftraixone, cephalaxin, cefotaxime, and cephazolin among cephalosporins.

In this report, we investigated the appropriateness of prescriptions of higher generation antibiotics (cephalosporin and flouroquonolone groups) in the outpatient setting of three referral hospitals of Bhutan.

\section{Materials and method}

This cross-sectional study using out-patient prescriptions was carried out between July and August, 2007 in Eastern Regional Referral Hospital (ERRH) located at Monggar, Central Regional Referral Hospital located at Gelephu, and Jigme Dorji Wangchuk National Referral Hospital (JDW/NRH) located at Thimphu in Western Bhutan. These referral hospitals have specialists in different fields such as medicine, surgery, gynecology, pediatric.

The outpatient prescriptions included patient details, clinical signs and symptoms, laboratory results, medications prescribed, and directions provided to the patients. All prescriptions containing antibiotics were collected from the pharmacy units during the medication collection time over a period of one month.

The prescriptions were used to determine the appropriateness of the medication as per the following ten criteria:

1 Is there an indication for the drug?

2 Is the medication effective for the condition?

3 Is the dosage correct?

4 Are the directions correct?

5 Are there clinically significant drug-drug interactions?

6 Are there clinically significant drug-disease interactions?

7 Are the directions practical?

8 Is this drug the least expensive alternative compared to others of equal utility?

9 Is there unnecessary duplication with other drugs?

10 Is the duration of therapy acceptable?
Each criterion was scored as either: appropriate, marginally appropriate and inappropriate. The MAI (Medication Appropriateness Index) was modified and adapted after discussion with Hospital Antibiotic Advisory Committee (HAAC). This tool has been tested for validity and reliability [12-14]. The HAAC members were called for a one-day meeting. After a brief explanation about the MAI criteria and its guidelines, they were divided into groups. The group consisted of three to four members from various specialties among the HAAC members. The groups made their decision based on the above- mentioned 10 criteria. After sorting, 333 prescriptions were analyzed.

This study was approved by the health research working group, which was the ethical clearing body for the Ministry of Health of Bhutan.

\section{Results}

Characteristics of the prescriptions for patients are shown in Table 1. On an average, 37.1\% of the prescription contained at least one antibiotic, out of which $13.8 \%$ prescriptions contained higher generation antibiotics. The prescriptions contained an average of 3.6 drugs per prescription. Only $14.7 \%$ of patients had co-morbidities. A total of $51.1 \%$ prescriptions were prescribed antibiotics on the first day of their visit, and only $2.7 \%$ of the prescriptions were prescribed after a culture sensitivity test.

Table 2 shows percentage score according to medication appropriateness index. For indication, $47.1 \%$ of the prescriptions had appropriate indication, $12.9 \%$ marginally appropriate, and $40.0 \%$ inappropriate. The finding for correctness of dosage, duration of therapy, interactions, and cost effectiveness were decided. The outcome assessed on the inappropriateness with weighted average of three and above considered as inappropriate, our study showed $55.9 \%$ of the prescriptions had inappropriate higher generation antibiotics prescribed. 
Table 1. Characteristics of the prescriptions.

\begin{tabular}{|c|c|c|}
\hline Variables & Frequency & Proportion \\
\hline$\%$ prescriptions with antibiotics & 3658 & 37.1 \\
\hline $\begin{array}{l}\% \text { prescriptions with higher generations } \\
\text { antibiotics out of antibiotics prescribed }\end{array}$ & 505 & 13.8 \\
\hline Mean age of patient & 9847 & $34.6(\mathrm{SD} 15.7)$ \\
\hline$\%$ females & 189 & 56.8 \\
\hline \% prescriptions with co morbidities & 49 & 14.7 \\
\hline$\%$ discharge prescription & 60 & 18 \\
\hline$\%$ prescriptions with culture sensitivity report & 9 & 2.7 \\
\hline $\begin{array}{l}\text { \% prescription prescribed with higher } \\
\text { generation antibiotics on first day } \\
\% \text { prescriptions prescribed other antibiotics }\end{array}$ & 170 & 51.1 \\
\hline $\begin{array}{l}\text { before higher generation antibiotics } \\
\% \text { higher generation antibiotics prescription }\end{array}$ & 74 & 22.2 \\
\hline in generics & 347 & 99.1 \\
\hline $\begin{array}{l}\% \text { higher generation antibiotics dispensed } \\
\text { from hospital }\end{array}$ & 313 & 94.0 \\
\hline $\begin{array}{l}\text { Average number of drugs prescribed/prescription } \\
\% \text { higher generation antibiotics prescribed }\end{array}$ & 9847 & 3.5(SD 1.6) \\
\hline $\begin{array}{l}\text { by specialist } \\
\% \text { higher generation antibiotics prescribed }\end{array}$ & 205 & 61.6 \\
\hline $\begin{array}{l}\text { by medical officers } \\
\text { \% higher generation antibiotics prescribed }\end{array}$ & 43 & 12.9 \\
\hline $\begin{array}{l}\text { by Assistant Clinical Officers } \\
\text { \% higher generation antibiotics prescribed }\end{array}$ & 57 & 17.1 \\
\hline by others including paramedics & 28 & 8.4 \\
\hline
\end{tabular}

Table 2. \% score according to medication appropriateness index.

\begin{tabular}{clllc}
\hline $\begin{array}{l}\text { Criterion } \\
\text { in the text }\end{array}$ & $\begin{array}{l}\text { Inappropriate } \\
\text { Number (\%) }\end{array}$ & $\begin{array}{l}\text { Marginally } \\
\text { appropriate } \\
\text { Number (\%) }\end{array}$ & Appropriate & Unknown \\
\hline 1 & Number (\%) & Number (\%) \\
\hline 2 & $133(40.0)$ & $43(12.9)$ & $157(47.1)$ & 0 \\
3 & $133(39.9)$ & $42(12.6)$ & $157(47.1)$ & $1(0.3)$ \\
4 & $136(40.8)$ & $2(0.6)$ & $194(58.3)$ & $1(0.3)$ \\
5 & $137(41.1)$ & $18(5.4)$ & $51(15.3)$ & $127(38.0)$ \\
6 & $137(41.1)$ & $2(0.6)$ & $68(20.4)$ & $126(37.8)$ \\
7 & $143(42.9)$ & $3(0.9)$ & $185(55.6)$ & $2(0.6)$ \\
8 & $133(39.9)$ & $1(0.3)$ & $199(59.8)$ & 0 \\
9 & $136(40.8)$ & 0 & $197(59.2)$ & 0 \\
10 & $141(42.3)$ & $1(0.3)$ & $188(56.5)$ & $3(0.9)$ \\
& $246(73.9)$ & $50(15.1)$ & $36(10.8)$ & $1(0.3)$ \\
\hline
\end{tabular}




\section{Discussion}

This study has shown a wide spread inappropriate use of higher generation antibiotics in Bhutan. The essential drug list of Bhutan specifically mentions that higher generation antibiotics should be prescribed only by the specialist after culture sensitivity result. However, our study revealed that on overall $55.6 \%$ of the prescriptions containing higher generation antibiotics are prescribed inappropriately. This indicates that the policies of the program are not followed by the prescriber.

Our study also revealed that $51.1 \%$ of the higher generation antibiotics were prescribed on the first day of the patient's visit and with only $2.7 \%$ of prescription having culture sensitive test done as mandated by the antibiotic policy. The EDP policy guideline states that all higher generation antibiotics must be prescribed only if there is evidence of resistance as indicated by culture sensitive test and only specialists are authorized to prescribe the higher generation antibiotics. However, 38\% of the prescriptions with higher generation antibiotics were prescribed by other health workers including of $17.1 \%$ that were prescribed by Assistant Clinical Officers. This indicates that although the guidelines and policies provide stewardship and guide the prudent use of antibiotics, it is not always followed. Therefore, to obtain good adherence, education and monitoring of all relevant people are indispensable.

It is well known that there is a high mean decreases in susceptibility to fluoroquinlones by $P$. aeruginosa and E.coli [16]. Inappropriate use of antibiotics seems to be a universal problem. A study conducted in Turkey showed that only $45.7 \%$ of the prescriptions prescribed for in-patient were rational [17]. Sandiumenge et al. [15] studied in the impact of different antibiotic strategies on acquisition of resistance microorganisms, and found that cephalosporins and quinolones accounted for $11.3 \%$ and $8.4 \%$, respectively, of all prescriptions for ventilator-associated pneumonia in Spain. Other similar studies indicated about $30-75 \%$ of prescriptions for higher generation antibiotics are inappropriate [18-20].

Our study has some limitations such as short duration of data collection, which could over represent few prescribers. In addition, some prescriptions did not contain all the required information especially on patient history to thoroughly determine the appropriateness. However, the present result showed that there is a huge inappropriate use of higher generation antibiotics in Bhutan. Therefore, urgent effective interventions are required to halt this rampant practice of inappropriate prescribing of higher generation antibiotics.

\section{Acknowledgement}

We would like to acknowledge the contributions of pharmacy staff and Bhutan Hospital Antibiotic Advisory Committee. Our gratitude to Dr. Joseph T. Hanlon, University of Pittsburg, for providing guidelines to the use of medication Appropriateness Index.

This study was sponsored by DBL-Institute for Health Research and Development, Denmark. There are no financial or other conflicts of interest associated with this article.

\section{References}

1. World Health Organization: WHO infectious disease report: leading cause of death. Vol. 2004, 1999.

2. Rubin MA, Samore MH. Antimicrobial use and resistance. Curr Infect Dis Rep. 2002; 4:491-7.

3. Cosgrove SE, Carmeli Y. The impact of antimicrobial resistance on health and economic outcomes. Clin Infect Dis. 2003; 36:1433-7.

4. World Health Organization: WHO global strategy for containment of antimicrobial resistance. WHO/CDS/ DRS/2001.2: WHO, Geneva, 2001.

5. Byarugaba DK. Antimicrobial resistance in developing countries and responsible risk factors. Int J Antimicrob Agents. 2004; 24:105-10.

6. Karlowsky JA, Kelly LJ, Thornsberry C, Jones ME, Sahm DF. Trends in antimicrobial resistance among urinary tract infection isolates of escherichia coli from female outpatients in the United States. Antimicrob Agents Chemother. 2002; 46:2540-5.

7. Niyogi SK, Dutta P, Mitra U. Trends in antimicrobial resistance of Shigella species isolated from children with acute diarrhea. Indian Pediatr. 2000; 37:339-41.

8. Okeke IN, Lamikanra A, Edelman R. Socioeconomic and behavioral factors leading to acquired bacterial resistance to antibiotics in developing countries. Emerg Infect Dis. 1999; 5:18-27.

9. Patel SJ, Larson EL, Kubin CJ, Saiman L. A review of antimicrobial control strategies in hospitalized and ambulatory pediatric populations. Pediatr Infect Disease J. 2007; 26: 531-7.

10. Capoor MR, Nair D, Deb M, Aggarwal P. Enteric fever perspective in India: emergence of high-level 
ciprofloxacin resistance and rising MIC to cephalosporins. J Med Microbiol. 2007; 56:1131-2.

11. Patrick DM, Marra F, Hutchinson J, Monnet DL, Ng H, Bowie WR. Per capita antibiotic consumption: how does a North American jurisdiction compare with Europe? Clin Infect Dis. 2004; 39:11-7.

12. Buetow SA, Sibbald B, Cantrill JA, Halliwell S. Appropriateness in health care: application to prescribing. Social Sci Med. 1997; 45:261-71.

13. Hanlon JT, Schmader KE, Samsa GP, Weinberger M, Uttech KM, Lewis IK, et al. A method for assessing drug therapy appropriateness. J Clin Epidemiol. 1992; 45: 1045-51.

14. Samsa GP, Hanlon JT, Schmader KE, Weinberger M, Clipp EC, Uttech KM, et al. A summated score for the medication appropriateness index: development and assessment of clinimetric properties including content validity. J Clin Epidemiol. 1994; 47: 891-6.

15. Sandiumenge A, Diaz E, Rodriguez A, Vidaur L, Canadell L, Olona M, et al. Impact of diversity of antibiotic use on the development of antimicrobial resistance. J Antimicrob Chemother. 2006; 57:1197-204.

16. Zervos MJ, Hershberger E, Nicolau DP, Ritchie DJ, Blackner LK, Coyle EA, et al. Relationship between fluoroquinolone use and changes in susceptibility to fluoroquinolones of selected pathogens in 10 United States teaching hospitals, 1991-2000. Clin Infect Dis. 2003; 37:1643-8.

17. Tunger O, Dinc G, Ozbakkaloglu B, Atman UC, Algun U. Evaluation of rational antibiotic use. Int J Antimicrob Agent. 2000; 15:131-5.

18. LeMire M, Wing L, Gordon DL. An audit of third generation cephalosporin prescribing in a tertiary care hospital. Aust N Z J Med. 1996; 26: 386-90.

19. Pickering TD, Gurwitz JH, Zaleznik D, Noonan JP, Avorn $\mathrm{J}$. The appropriateness of oral fluoroquinoloneprescribing in the long-term care setting. J Am Geriatr Soc. 1994; 42: 28-32.

20. Pinto Pereira L, Phillips M, Ramlal H, Teemul K, Prabhakar P. Third generation cephalosporin use in a tertiary hospital in Port of Spain, Trinidad: need for an antibiotic policy. BMC Infect Dis. 2004; 4:59. 